\title{
Comparison of Duration of Activity of Corticotrophin-Gelatin and Corticotrophin-Carboxymethylcellulose
}

\author{
M. FRIEDMAN,* M.D., M.R.C.P.ED.
}

Brit. med. F., 1967, 3, 409-410

Corticotrophin is rapidly destroyed in the blood stream. Several substances have been added to corticotrophin in order to prolong its duration of action. These substances act at the site of injection and delay the release or destruction of corticotrophin. In the United Kingdom gelatin and zinc preparations of corticotrophin have been in use for many years. Recently a preparation of corticotrophin with the addition of carboxymethylcellulose (Crooks A.C.T.H./c.m.c.) has been introduced in this country. The manufacturers have claimed that this preparation "lasts like" the gelatin preparation. An investigation has been undertaken in normal healthy volunteers to test the validity of this claim.

\section{Methods}

The investigation was carried out on 10 normal healthy volunteer subjects (two women and eight men) aged 22 to 35 years. They continued with their normal activities; there were no restrictions on diet or activity during investigation. Each subject was given $2 \mathrm{mg}$. of dexamethasone daily in four divided doses on the two days preceding the test and on the day of the test to suppress endogenous corticotrophin release. At 09.00 hours on the day of the test each subject was given either 40 international units of a gelatin-corticotrophin preparation (Acthar Gel Armour Batch No. KG. 2802) or 40 international units of corticotrophin-carboxymethylcellulose preparation (Crooks A.C.T.H./c.m.c. Batch No. 65091) by deep intramuscular injection. After an interval of seven days a second test was carried out under identical conditions administering the corticotrophin preparation not received in the first test. The initial preparation used in each subject was randomly selected. Blood samples were taken before and at 1, 3, 5, 7, 9, 12, and 15 hours after the injection of corticotrophin for the measurement of plasma 11-hydroxycorticosteroid concentration by the method of Mattingly (1962): Urine was collected in two sixhour periods after the corticotrophin injection for measurement of the urine 11-hydroxycorticosteroid concentration by the method of Mattingly et al. (1964).

\section{Results}

The plasma 11-hydroxycorticosteroid levels after the corticotrophin carboxymethylcellulose and gelatin preparations are given in Table I. Table II shows the urinary 11-hydroxycorticosteroid levels. The Chart shows the mean of the results obtained in the 10 subjects with the standard error of the mean.

A $t$ test on means of the paired differences in plasma 11hydroxycorticosteroid levels of all subjects at each time after the administration of corticotrophin showed that the gelatin preparation produced a greater rise of plasma 11-hydroxycorticosteroids than the carboxymethylcellulose preparation at $5,7,9$, and 12 hours ( 5 hours $P<0.05,7$ hours $P<0.05$, 9 hours $\mathbf{P}<0.01,12$ hours $\mathbf{P}<0.02$ ). At 1,3 , and 15 hours the differ-

\footnotetext{
- Paediatric Department, University College Hospital, London W.C.1, and Whittington Hospital, London N.19.
}

ences were not significant ( 1 hour $\mathrm{P}<0.1,3$ hours $\mathrm{P}<0.1$, 15 hours $\mathrm{P}<0.1$.

A $t$ test performed on means of the paired differences in urinary 11-hydroxycorticosteroid excretion in 9 of the 10 subjects showed that there was not a significant difference in the urinary excretion of free 11-hydroxycorticosteroids during the first six hours after administration of the two types of corticotrophin $(\mathrm{P}<0.1)$. During the second six hours the

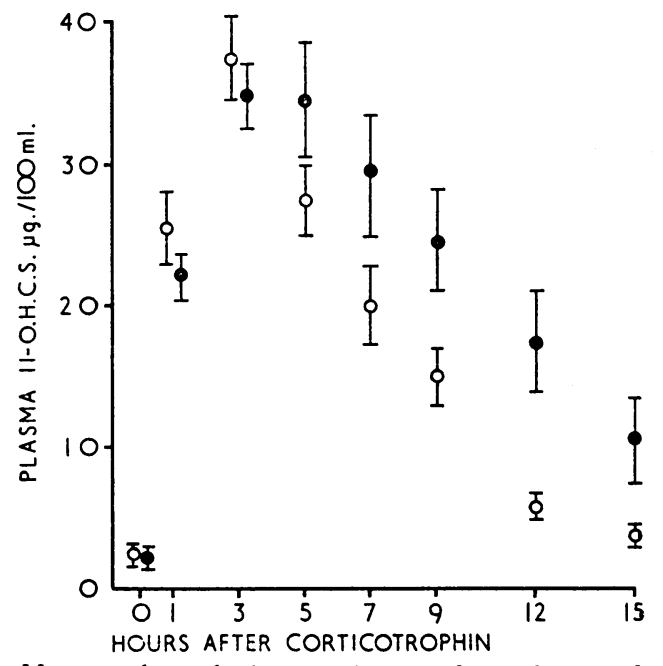

Means and standard error of means for each type of corticotrophin. The open circles represent the values obtained with carboxymethylcellulose and the closed circles the values with the gelatin preparation.

gelatin preparation produced a greater excretion of 11-hydroxycorticosteroids than the carboxymethylcellulose preparation $(\mathrm{P}<0.05)$.

\section{Discussion}

Intramuscular injection of corticotrophin in saline produces a maximal adrenal-stimulating effect in two hours with a fall in plasma steroids to control levels in four to six hours (Bayliss and Steinbeck, 1954). The short duration of effect is due to enzymatic destruction of the corticotrophin at the site of injection or in the blood stream. The instability of the saline preparations has stimulated the search for long-acting preparations. The addition of a number of substances to corticotrophin has been shown to increase the duration of activity either by delaying the release of corticotrophin or by inhibiting enzymatic destruction of the corticotrophin at the site of injection. Aluminium phosphate in polyvinyl pyrrolidine (Wolfson et al., 1951), procaine (Holbrook, 1951), cellulose and carboxymethylcellulose (Payne et al., 1951 ; Nordström and Jensen, 1954), oils (Raben et al., 1952), and gelatin (Raben et al., 1952) have all been shown to enhance corticotrophin activity, probably by delaying release at the site of injection. The addition of zinc compounds to corticotrophin is thought to inhibit enzymatic destruction at the site of injection (Ferriman et al., 1954 ; Homan et al., 1954). The therapeutic efficiency of any individual preparation of corticotrophin is related to the con- 
TABLE I.-Plasma 11-hydroxycorticosteroid Levels Expressed as $\mu \mathrm{g} . / 100 \mathrm{ml}$. Plasma, at Intervals after Intramuscular Injection of 40 i.u. Corticotrophin-carboxymethylcellulose and Gelatin in 10 Normal Healthy Subjects

\begin{tabular}{|c|c|c|c|c|c|c|c|c|c|c|c|c|c|}
\hline \multirow{2}{*}{$\begin{array}{c}\text { Type of } \\
\text { Corticotrophin }\end{array}$} & \multirow{2}{*}{$\begin{array}{l}\text { Hours } \\
\text { after } \\
\text { Injec- } \\
\text { tion }\end{array}$} & \multicolumn{10}{|c|}{ Subject } & \multirow[b]{2}{*}{ Mean } & \multirow{2}{*}{$\begin{array}{l} \pm 1 \text { S.E. } \\
\text { of Mean }\end{array}$} \\
\hline & & $\stackrel{1}{M}$ & $\stackrel{2}{M}$ & $M^{3}$ & $\stackrel{4}{M}$ & $\stackrel{5}{M}$ & $\stackrel{6}{M}$ & $\stackrel{7}{M}$ & $\stackrel{8}{\mathrm{~F}}$ & $\stackrel{9}{\mathrm{~F}}$ & $\stackrel{10}{M}$ & & \\
\hline $\begin{array}{l}\text { Carboxymethyl } \\
\text { cellulose }\end{array}$ & $\begin{array}{r}0 \\
1 \\
3 \\
5 \\
7 \\
9 \\
12 \\
15 \\
0 \\
1 \\
3 \\
5 \\
7 \\
9 \\
12 \\
15\end{array}$ & $\begin{array}{r}1 \cdot 8 \\
31 \cdot 4 \\
37 \cdot 4 \\
34 \cdot 0 \\
23.6 \\
12 \cdot 2 \\
7 \cdot 2 \\
4 \cdot 2 \\
2 \cdot 4 \\
24 \cdot 0 \\
34 \cdot 0 \\
41 \cdot 8 \\
33 \cdot 2 \\
29 \cdot 8 \\
15.0 \\
8.4\end{array}$ & $\begin{array}{r}2 \cdot 2 \\
21 \cdot 4 \\
29 \cdot 6 \\
26 \cdot 4 \\
24 \cdot 4 \\
19 \cdot 2 \\
10 \cdot 0 \\
6 \cdot 6 \\
2 \cdot 0 \\
20 \cdot 4 \\
30 \cdot 2 \\
33 \cdot 0 \\
32 \cdot 4 \\
31 \cdot 8 \\
21 \cdot 2 \\
9 \cdot 4\end{array}$ & $\begin{array}{r}3.4 \\
34.8 \\
52.6 \\
33.6 \\
20.0 \\
14.8 \\
7.0 \\
5.0 \\
4.0 \\
22.0 \\
41.0 \\
45.2 \\
36.4 \\
24.8 \\
10.6 \\
8.4\end{array}$ & $\begin{array}{r}4 \cdot 0 \\
34 \cdot 6 \\
49 \cdot 2 \\
30 \cdot 6 \\
23 \cdot 6 \\
18 \cdot 8 \\
6 \cdot 8 \\
3 \cdot 6 \\
1 \cdot 8 \\
29 \cdot 6 \\
48 \cdot 2 \\
27 \cdot 0 \\
29 \cdot 2 \\
30 \cdot 0 \\
25 \cdot 4 \\
14 \cdot 2\end{array}$ & $\begin{array}{r}2 \cdot 0 \\
18.6 \\
32.0 \\
20.6 \\
20 \cdot 0 \\
10.6 \\
5.8 \\
3.6 \\
1.6 \\
17.0 \\
23.4 \\
13.2 \\
8.0 \\
5.4 \\
4.0 \\
3.6\end{array}$ & $\begin{array}{r}3.4 \\
29.8 \\
48 \cdot 6 \\
33.8 \\
31.6 \\
26.8 \\
8.4 \\
4.6 \\
1.4 \\
21.4 \\
28 \cdot 6 \\
30 \cdot 8 \\
33.0 \\
28 \cdot 2 \\
17 \cdot 0 \\
6.2\end{array}$ & $\begin{array}{r}3 \cdot 6 \\
29 \cdot 8 \\
36.0 \\
20 \cdot 2 \\
9.6 \\
6.4 \\
3 \cdot 0 \\
2 \cdot 8 \\
3.4 \\
18 \cdot 6 \\
42 \cdot 8 \\
40 \cdot 2 \\
29 \cdot 6 \\
18.4 \\
13 \cdot 2 \\
6.8\end{array}$ & $\begin{array}{r}2 \cdot 2 \\
25 \cdot 8 \\
27 \cdot 6 \\
29 \cdot 2 \\
20 \cdot 6 \\
14 \cdot 2 \\
6 \cdot 0 \\
3 \cdot 8 \\
2 \cdot 0 \\
19 \cdot 4 \\
34 \cdot 2 \\
41 \cdot 2 \\
42 \cdot 4 \\
36 \cdot 2 \\
40 \cdot 4 \\
36 \cdot 2\end{array}$ & $\begin{array}{r}2 \cdot 2 \\
20 \cdot 4 \\
40 \cdot 6 \\
32 \cdot 4 \\
23 \cdot 8 \\
19 \cdot 8 \\
6 \cdot 8 \\
4 \cdot 2 \\
3 \cdot 2 \\
31 \cdot 8 \\
43 \cdot 6 \\
56 \cdot 2 \\
44 \cdot 4 \\
35 \cdot 4 \\
26 \cdot 4 \\
13 \cdot 2\end{array}$ & $\begin{array}{r}3 \cdot 8 \\
13 \cdot 2 \\
20 \cdot 8 \\
14 \cdot 2 \\
8 \cdot 6 \\
6 \cdot 6 \\
4 \cdot 6 \\
2 \cdot 2 \\
2 \cdot 4 \\
17 \cdot 2 \\
27 \cdot 2 \\
16 \cdot 0 \\
7 \cdot 2 \\
4 \cdot 4 \\
2 \cdot 2 \\
2 \cdot 0\end{array}$ & $\begin{array}{r}2.9 \\
25.7 \\
37.4 \\
27.5 \\
20.6 \\
14.9 \\
6.5 \\
4.0 \\
2.4 \\
22.1 \\
35.3 \\
34.5 \\
29.5 \\
24.4 \\
17.5 \\
10.8\end{array}$ & $\begin{array}{l}0.3 \\
2.3 \\
3.3 \\
2.2 \\
2 \cdot 2 \\
2 \cdot 0 \\
0 \cdot 6 \\
0.3 \\
0.2 \\
1.6 \\
2.6 \\
4 \cdot 1 \\
4 \cdot 0 \\
3.6 \\
3.6 \\
3.0\end{array}$ \\
\hline
\end{tabular}

TABLE II.-Urinary Free 11-hydroxycorticosteroids Expressed as $\mu g$. per Hour. Each Value Represents the Mean Excretion Over a Six-hour Period

\begin{tabular}{|c|c|c|c|c|c|c|c|c|c|c|c|c|c|}
\hline \multirow{2}{*}{$\begin{array}{c}\text { Type of } \\
\text { Corticotrophin }\end{array}$} & \multirow{2}{*}{$\begin{array}{c}\text { Hours } \\
\text { after } \\
\text { Injec- } \\
\text { tion }\end{array}$} & \multicolumn{10}{|c|}{ Subject } & \multirow{2}{*}{ Mean } & \multirow{2}{*}{$\begin{array}{l} \pm 1 \text { S.E } \\
\text { of Mean }\end{array}$} \\
\hline & & 1 & 2 & 3 & 4 & 5 & 6 & 7 & 8 & 9 & 10 & & \\
\hline $\left.\begin{array}{l}\text { Carboxymethyl } \\
\text { cellulose } \\
\text { Gelatin }\end{array}\right\}$ & $\begin{array}{l}0-6 \\
6-12 \\
0-6 \\
6-12\end{array}$ & $\begin{array}{l}44 \cdot 2 \\
12 \cdot 0 \\
43 \cdot 6 \\
23 \cdot 7\end{array}$ & $\begin{array}{l}12 \cdot 4 \\
20.7 \\
14.9 \\
34.0\end{array}$ & $\begin{array}{r}29 \cdot 4 \\
8 \cdot 5 \\
28 \cdot 2 \\
34 \cdot 2\end{array}$ & $\begin{array}{l}39 \cdot 4 \\
16.9 \\
18 \cdot 6 \\
25 \cdot 2\end{array}$ & $\begin{array}{r}12 \cdot 6 \\
8.6 \\
5.7 \\
5.0\end{array}$ & $\begin{array}{l}53.4 \\
32.6 \\
36.8 \\
54.5\end{array}$ & $\begin{array}{r}18 \cdot 9 \\
4 \cdot 6 \\
15 \cdot 0 \\
16 \cdot 0\end{array}$ & $\begin{array}{r}\overline{ } \\
25 \cdot 7 \\
74 \cdot 4\end{array}$ & $\begin{array}{l}14 \cdot 0 \\
14 \cdot 0 \\
13 \cdot 8 \\
34 \cdot 3\end{array}$ & $\begin{array}{r}12.5 \\
15 \cdot 2 \\
10 \cdot 2 \\
3.9\end{array}$ & $\begin{array}{l}26 \cdot 3 \\
14 \cdot 8 \\
21 \cdot 3 \\
30 \cdot 0\end{array}$ & $\begin{array}{l}5 \cdot 3 \\
2 \cdot 3 \\
3 \cdot 8 \\
6 \cdot 8\end{array}$ \\
\hline
\end{tabular}

centration of corticotrophin and duration of activity, the latter being determined by the carrier vehicle.

A number of factors must be taken into account when comparing the corticotrophin preparations. Considerable variation in individual response to corticotrophin occurs (Bayliss and Steinbeck, 1954). In the present study this is shown by Subject 5 (Table I), who reacted differently from all the other subjects with respect to his response to the gelatin and carboxymethylcellulose preparation. The standardization of different preparations of corticotrophin may vary from batch to batch and from manufacturer to manufacturer. However, the carrier vehicle for corticotrophin is comparably much more important than minor variations in concentration. DiRaimondo and Forsham (1958) have shown that doubling the corticotrophin dose of a gelatin preparation prolongs the increase in steroidogenesis by approximately one hour. In the present study the gelatin preparation appears to be superior to the carboxymethylcellulose preparation at $5,7,9$, and 12 hours. This difference suggests that gelatin is superior to carboxymethylcellulose in delaying release of corticotrophin from the site of injection and prolonging corticotrophin activity.

Hangård et al. (1960), investigating the effect of response of different types of repository corticotrophin preparations, including gelatin and carboxymethylcellulose, were unable to draw definite conclusions from their study. They suggest that individual variations in response and unequal potency of different preparations make comparative studies difficult. In their study they did not inhibit endogenous corticotrophin by pituitary suppression, which introduced a further variable. Hedner (1963) found that a corticotrophin-gelatin preparation had a significantly longer duration of action compared with a preparation of carboxymethylcellulose in equivalent dosage.

Because of its low viscosity, carboxymethylcellulose can be drawn up into a syringe and injected with ease. No prior warming of the preparation is required. This is an advantage. The gelatin preparation, however, has a high viscosity and requires warming before administration. Furthermore, the gelatin may solidify in the syringe, and if not injected soon after warming this may lead to some of the preparation being lost from the joint between the needle and the syringe if excessive force is used during the injection.

The present investigation and the published data available suggest that corticotrophin-carboxymethylcellulose does not have the same duration of activity as the gelatin preparation and is likely to be inferior therapeutically if used in equivalent dosage. Caution should be exercised when changing from one preparation to another in equivalent doses. At present carboxymethylcellulose does not seem to offer any therapeutic advantage over the gelatin preparation. The claim that carboxymethylcellulose "lasts like gel" is not substantiated.

\section{Summary}

A comparison has been made of the potency and duration of activity of two preparations of corticotrophin, one combined with gelatin and the other with carboxymethylcellulose. The plasma and urinary 11-hydroxycorticosteroid levels were measured in 10 normal subjects after an intramuscular injection of 40 international units of each preparation. The duration of activity of the carboxymethylcellulose preparation was less than that of the gelatin preparation in 9 out of the 10 subjects. Caution should be exercised when changing from one preparation to another in equivalent doses.

I am grateful to Crooks Laboratories Limited for supplies of carboxymethylcellulose preparation (Crooks A.C.T.H./c.m.c.) used in this study.

\section{REFERENCES}

Bayliss, R. I. S., and Steinbeck, A. W. (1954). Brit. med. 7., 1, 486. DiRaimondo, V. C., and Forsham, P. H. (1958). Metabolism, 7, 5.

1, 545 . 168, 205 .

Hedner, P. (1963). Acta endocr. (Kbh.), 43, 499.

Holbrook, W. P. (1951). Proceedings of the 2 nd Clinical A.C.T.H. Conference, 11, 24. Philadelphia.

Homan, J. D. H., Overbeek, G. A., Neutelings, J. P. J., Booij, C. J., and van der Vies, J. (1954). Lancet, 1, 541

Mattingly, D. (1952). f. clin. Path., 15, 374.

Mattingly, D. (1964). Lancet, 2, 1046.

Nordström, S., and Jensen, C. C. (1954). Svenska Läk.-Tidn. 51, 2196. Nordström, S., and Jensen, C. C. (1954). Suenska Lak.-Tidn. A. P., and Payne, R. W., Rosenberg, I. N., Raben, M. S., C

Astwood, E. B. (1951). I. clin. Westermeyer, V. W., and Astwood, E. B. (1952). 7. Amer. med., Ass., 148, 844.

Wolfson, W. Q., Thompson, R. E., Robinson, W. D., Duff, I. E., Cohn, C., Lewis, L., and Hunt, H. D. (1951). Proceedings of the 2 nd Clinical A.C.T.H. Conference, 11, 2. Philadelphia. 